\title{
Salivary Flow Rate Before, During and After Insertion of Complete Denture in Different Age Group: a Comparative study
}

\section{Dibya Devkota ${ }^{1}$, Suraj Ram Bhakta Mathema ${ }^{2}$,Laxman Bhusal ${ }^{3}$}

\author{
Author Info: \\ ${ }^{1}$ Department of Prosthodontics \\ and Maxillofacial Prosthetics, \\ People's Dental College And \\ Hospital, \\ ${ }^{2}$ Department of Prosthodontics \\ and Maxillofacial Prosthetics, \\ People's Dental College And \\ Hospital \\ ${ }^{3}$ Department of Emergency \\ Medicine, Shree Birendra \\ Hospital, Chauni \\ *Corresponding Author: \\ Dr. Dibya Devkota \\ Email/Contact: \\ dibyadevkota72@gmail.com \\ +977-9847059756
}

\begin{abstract}
Background: Increase in salivary flow accompanying complete denture insertion is a well-known phenomenon. Complete dentures act as a mechanical stimulant, increasing salivary flow after insertion. This study compares unstimulated and stimulated salivary flow rates before, during, and after insertion of a complete denture in different age groups.

Method: Forty subjects meeting inclusion criteria were selected. Unstimulated saliva was collected first. Stimulation was produced by chewing paraffin wax and collected of saliva in a graduated container. This procedure was carried out before insertion, during insertion, 24 hours after, and 7 days after insertion of complete dentures. The study data were entered, edited, and coded in Microsoft Excel. The unstimulated and stimulated salivary flow rate was compared at different time intervals.

Result: Unstimulated salivary rate was lowest before denture insertion with mean values of $0.27 \mathrm{ml} / \mathrm{minute}$. The highest flow rate was recorded during denture insertion (mean values of $0.60 \mathrm{ml} /$ minute). The mean unstimulated salivary flow rate 24 hours after denture insertion was higher than 7 days after denture insertion. The mean stimulated salivary rate was lowest before denture insertion (mean values of $0.59 \mathrm{ml} /$ minute). The highest flow rate was recorded during denture insertion (mean values of $0.93 \mathrm{ml} /$ minute). There was a declining trend in salivary flow rate after denture insertion i.e. $0.86 \mathrm{ml} /$ minute to $0.75 \mathrm{ml} / \mathrm{min}$ after 24 hours and 7 days of denture insertion. A gradual decrease in salivary flow rate with an increase in age was noted but the association of age with salivary flow rates was not statistically significant.
\end{abstract}

Conclusion: There was an increase in both unstimulated and stimulated salivary flow rate after insertion of complete denture and age does not affect salivary flow rates before, during (immediately after), 24 hours after, and 7 days after denture insertion.

Keywords: Complete Dentures, Salivary Flow Rates

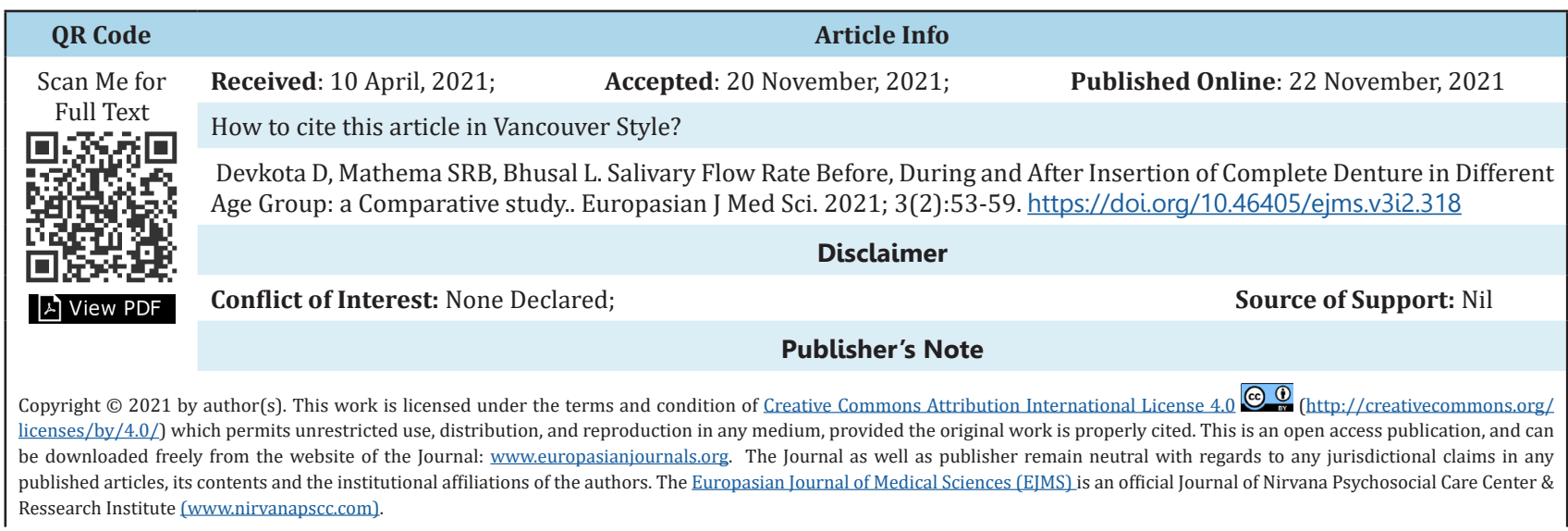




\section{INTRODUCTION}

Saliva is a clear, slightly acidic mucoserous exocrine secretion. Three paired exocrine glands namely; the parotid, submandibular and sublingual glands secrete saliva in our body. ${ }^{1}$ There is a secretion of 1-1.5 Ltr of saliva in twenty-four-hour. ${ }^{2}$ The total average volume secreted consists of both unstimulated and stimulated saliva. Unstimulated saliva is defined as the saliva collected with no apparent source of stimulation. Stimulated saliva is defined as the saliva produced in response to different stimuli. The most commonly used stimulants are paraffin wax, rubber bands, gum base, and citric acid. ${ }^{3}$

Denture integrity is preserved by saliva by its cleansing action that washes away food and other debris from the soft tissues and the surface of the prosthesis. Saliva makes the surface of the dentures more compatible by its lubrication in the movements of the lips, cheek, and tongue. The movement of soft tissues is facilitated by salivary glycoproteins during speech, mastication, and swallowing of food. ${ }^{1}$

Thin-film of saliva between the dentures and oral mucosa helps in retention of the dentures. Physical factors of retention - adhesion, cohesion, interfacial surface tension and capillarity come into play because of a thin film of saliva and aids in the retention of dentures. There is a profound effect on denture retention and stability in decreased salivary flow and it also tends to make mastication and deglutition difficult. Loss of the mechanical protective influence of saliva on the denture supporting tissues would predispose them to irritation. The antibacterial action provided by saliva would be proportionally reduced making the denture-bearing oral tissues more susceptible to infection. The importance of this film is evident from the multitude of problems associated with denture wear in the xerostomic patient. Soreness and ulceration of the denture-bearing tissues, decreased denture retention, burning sensations, alterations in taste perception, and difficulty in mastication and swallowing are among the problems encountered by these patients. ${ }^{4}$ Considering the highly significant role played by saliva in successful complete denture rehabilitation, the prosthodontist must give due attention to the quantity and quality of saliva during the fabrication of complete dentures. Hypo-salivation and associated xerostomia is common finding in the elderly. Such conditions must be identified before denture fabrication and a treatment plan may be needed to be modified accordingly.

Numerous studies have been done around the world for the assessment of salivary flow rate before and after the insertion of complete dentures in different age groups..$^{5-7}$ It has been a matter of debate whether salivary flow rates are affected with age. As age progresses, the proportional volume of fat and fibrovascular tissue increases in both the parotid and submandibular glands, and the proportional volume of acini is reduced. ${ }^{8}$ These extensive glandular changes would be expected to have functional manifestations. However, the opinions of different authors are contradictory. No such study has been done in the Nepalese context. This study aims to compare the flow rate of unstimulated and stimulated saliva in the Nepalese populations of different age groups.

\section{MATERIALS AND METHODS}

Simple random sampling was done with an enrollment of participants who presented with complete edentulous at the first visit in OPD at People's Dental College. The sample size was calculated with mean and standard deviation based on a reference article by $A$. Wolff et al with a sample of 40 cases. This study was conducted in the Department of Prosthodontics \& Maxillofacial Prosthetics, People's Dental College \& Hospital. Before commencement of the study, an approval letter was obtained from Institutional Review Board, Institute of Medicine (IOM) with reference no 87(6$11-E)^{2}, 874 / 875$. The duration of the study was one year. For all the selected participants' informed consent was taken. Patients with completely edentulous subjects who want fabrication of complete denture and patients who agree for voluntary participation for the study were included in the study. Patients with a history of medical conditions that decrease salivary flow (uncontrolled diabetes, Parkinson's disease, etc.), patients taking neuroleptic drugs and anti-depressants drugs, patients with a history of salivary gland disorders, and patients with a history of radiation therapy are excluded from the study.

Participants were refrained from eating, drinking, and smoking 1 hour before the procedure. The timing of saliva collection was standardized for all subjects is between $1 \mathrm{pm}$ to $4 \mathrm{pm}$. Unstimulated saliva was collected first. Subjects were seated comfortably in the upright positions. Then $5 \mathrm{ml}$ of clean drinking water was provided in the disposable cup to swish in the mouth for 5 seconds. After spitting the water and initial swallow subjects were instructed not to swallow but spit the saliva 
in the graduated container provided. The subjects were instructed to spit the saliva in the graduated tube every minute for 10 minutes. At the end of 10 minutes, the volume of saliva collected was noted and the flow rate was determined as volume collected per time. For the collection of stimulated saliva, subjects were instructed to chew on a piece of a paraffin wax block for 2 minutes. At the completion, the subjects were instructed to spit the saliva collected in the graduated tube. The volume of saliva collected was noted and the flow rate was calculated in $\mathrm{ml} / \mathrm{min}$. This procedure was carried out at 4 appointments i.e., Before insertion of the complete denture, During insertion (immediately after insertion),24 hours after insertion, and 7 days after insertion. The study data were entered, edited, and coded in Microsoft Excel. The continuous variables like salivary flow rate, age, etc. were summarized using mean and standard deviation while the categorical variables like sex were summarized in percentages and displayed with the help of frequency distribution tables. The stimulated and unstimulated salivary flow rate at different time intervals (betweengroup) was compared. Salivary flow rates within the groups at four separate time intervals between different age groups and sex was compared. The level of significance was set at $5 \%$.

\section{RESULTS}

The majority of the patients belonged to the age group of 60 - 70 years followed by 50 - 60 years and less than 10 percent of patients were less than 50 years of age (Fig 1). The unstimulated salivary rate was lowest before denture insertion with mean values of $0.27 \mathrm{ml} /$ minute with values ranging from 0.08 to 0.70 . The highest flow rate was recorded during denture insertion with mean values of 0.60 $\mathrm{ml} /$ minute and values ranging from 0.26 to 1.28 . The mean unstimulated salivary flow rate 24 hours after denture insertion was higher than 7 days after denture insertion.

The mean stimulated salivary rate was lowest before denture insertion with mean values of 0.59 $\mathrm{ml} /$ minute with values ranging from 0.18 to 1.50 . The highest flow rate was recorded during denture insertion with mean values of $0.93 \mathrm{ml} /$ minute and values ranging from 0.24 to 2.40 . There was a declining trend in salivary flow rate i.e. $0.86 \mathrm{ml} /$ minute to $0.75 \mathrm{ml} / \mathrm{min}$ after 24 hours and 7 days of denture insertion. During all the time intervals, the salivary flow rate in the stimulated condition is higher than in unstimulated conditions. In both conditions, the highest flow rate was observed

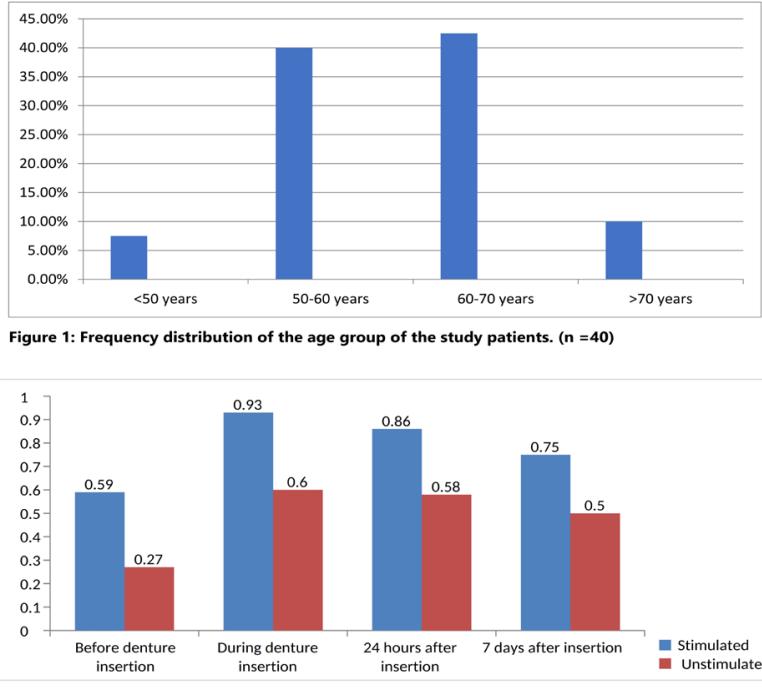

Figure 2: Salivary flow in Stimulated and Unstimulated before, during, 24 hours after insertion, and 7 days after insertion.

during insertion while the lowest was observed before denture insertion. Analyses show that mean stimulated salivary flow rates were significantly higher than the unstimulated salivary rate before, during, and after denture insertion with a p-value less than 0.001 . The highest difference in mean flow rates $(0.330 \mathrm{ml} / \mathrm{min})$ was during insertion of a denture and lowest 7 days after denture insertion (0.271 $\mathrm{ml} / \mathrm{min})$. This signifies that stimulation can cause a significant increase in salivary flow rates among edentulous patients [Fig 2].

During all the time intervals, the salivary flow rate in the stimulated conditions was higher than in unstimulated conditions. In both conditions, the highest flow rate was observed during insertion while the lowest was observed before denture insertion [Fig 2].

The salivary flow rate findings of different age group suggest that stimulated salivary flow rate was higher among edentulous patients of 50 to 60 years and then it started to decline at higher age groups i.e. from 60 - 70 age group to $70-80$ age group. On the other hand, no such trend was observed in the unstimulated salivary flow rate. In both the conditions, an association of age with salivary flow rates was not statistically significant implying no effect of age on salivary flow rates before denture insertion [Table 1].

The findings of salivary flow rate among different age groups during insertion suggest that stimulated salivary flow rate was highest among edentulous patients below 50 years of age and then it started to decline at higher age groups i.e. from 50 - 60 to $60-70$, till > 70 years age group. On the other hand, no such trend was observed 
Table 1, Comparison of age an falivary flaw rates before denture insertion in = 40)

\begin{tabular}{|c|c|c|c|c|c|c|}
\hline \multirow{2}{*}{$\begin{array}{l}\text { Aot group in } \\
\text { peas }\end{array}$} & \multicolumn{3}{|c|}{ Stimulated llow rate } & \multicolumn{3}{|c|}{ Unotimulated for rate } \\
\hline & 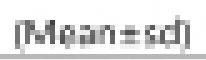 & Fontistif & P upluk & [Mตดก \pm แ| & F staphtic & P value \\
\hline 50 ymars & $0.58+025$ & 1545 & 0220 & $0.30=0.95$ & 0703 & 0.557 \\
\hline 50 - 40 pors & $0.55 \pm 0.22$ & & & $0.27=0.14$ & & \\
\hline $60-70$ years & $0.61 \pm 0.00$ & & & $0.29=0.13$ & & \\
\hline $70-60$ years & $0.30 \pm 0.08$ & & & $0.19 \pm 0.03$ & & \\
\hline
\end{tabular}

Table 2 Compurison of mean age on Glivary flow rates during denture insertion (n - 40)

\begin{tabular}{|c|c|c|c|c|c|c|}
\hline \multirow[t]{2}{*}{ Aje group } & \multicolumn{3}{|c|}{ Stimulated flow rate } & \multicolumn{3}{|c|}{ Whstimileted flow rate } \\
\hline & 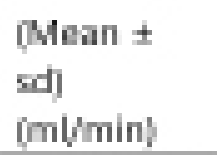 & F statistic & P ualuh & $\begin{array}{l}\text { Monn } \pm \text { dy } \\
\text { tmbljming }\end{array}$ & F sint stic & P walue \\
\hline SD yours & $1.09=0.31$ & 1..441 & adse & $0.63 \pm 0.11$ & 4.449 & 0509 \\
\hline 50 - 00 years & $0.91=0.43$ & & & $0.59 \pm 0.27$ & & \\
\hline 60-70pears & $0.99 \pm 0.42$ & & & $063 \pm 023$ & & \\
\hline mo yors & $0.62=0.26$ & & & $0.45 \pm 0.24$ & & \\
\hline
\end{tabular}

Table In Comparison of mesn of age on salivary flow rates 24 hours after denture insertion Age graup Stimulated flow rate Unatimulated foris rate

|Mesn \pm rdi Fstatiotic Pralue [Mean \pm gd] Fstatistic Pwolue [milmin] ¿mlimin!

\begin{tabular}{|c|c|c|c|c|c|c|}
\hline 45 yedrs & $105 \pm 0.45$ & 0.923 & 0.40 & $0.70=0.45$ & 0225 & 0879 \\
\hline 50-60 years & $0.81+0.36$ & & & $0.84=1.28$ & & \\
\hline $60-70$ years & $0.93 \pm 0.22$ & & & $0.64=0.27$ & & \\
\hline$=70$ years & $0.67 \pm 0.16$ & & & $0.52=0.19$ & & \\
\hline
\end{tabular}

Table 4: Effect of ane on salivary flow rates 7 days after denture insertion. $6 n=40$ )

\begin{tabular}{|c|c|c|c|c|c|c|}
\hline \multirow[t]{3}{*}{ Aget group } & \multicolumn{3}{|c|}{ Simplated flow bate } & \multicolumn{3}{|c|}{ Unstinulated flow rate } \\
\hline & Mean \pm sh & F shition & P value & Mear \pm 50 & F gtathte & Puglus \\
\hline & \multicolumn{3}{|l|}{ tombing } & \multicolumn{3}{|l|}{ [nthirin } \\
\hline ad years & $0.74 \pm 0.16$ & 0614 & D.L10 & $0.45 \pm 0.11$ & D.591 & D.sS \\
\hline 50 -60 years & $0.75 \pm 0.37$ & & & $051 \pm 023$ & & \\
\hline 60-70 yedrs & $079 \pm 0.31$ & & & $0.75 \pm 095$ & & \\
\hline so years & $0.55 \pm 0.06$ & & & $018 \pm 00$ & & \\
\hline
\end{tabular}

in the unstimulated salivary flow rate. In both the 
conditions, an association of age with salivary flow rates was not statistically significant implying no effect of age on salivary flow rates during denture insertion [Table 2].

The findings of salivary flow rates among patients of different age groups in 24 hours after denture insertion suggest that stimulated salivary flow rate was highest among edentulous patients below 50 years of age and then it started to decline at higher age groups i.e. from $50-60$ to 60 - 70 till $>70$ years age group. The unstimulated salivary flow rate was highest among patients of 50-60 years and started to decline in subsequent higher age groups. In both the conditions, an association of age with salivary flow rates was not statistically significant implying no effect of age on salivary flow rates 24 hours after denture insertion [Table 3]

The findings of salivary flow rates among patients of different age groups 7 days after insertion suggest that salivary flow rate was lowest for age the group i.e. $>70$ years and highest for age the group of 60 - 70 years of age group in both stimulated and stimulated conditions. However, the association of age with salivary flow rates was were statistically significant implying no effect of age on salivary flow rates 7 days after denture insertion [Table 4].

\section{DISCUSSION}

The role of saliva is very important in maintaining the homeostasis of the oral cavity. It exerts antimicrobial effects, helps maintain normal oral ecology, $\mathrm{pH}$, tooth and mucosal integrity. It also mediates taste sensations and assists in mastication and deglutition through its lubricative property. ${ }^{10}$ In removable prosthodontics, it is critical for retention of dentures and to provide comfort while wearing removable prostheses.

An increase in salivary flow rate accompanying the insertion of an initial set of complete dentures is a well-known phenomenon. Complete denture acts as a mechanical stimulant thus increasing the salivary flow rate immediately after complete denture insertion. ${ }^{11}$ As different authors and studies have advocated variable salivary flow rate before, during, and after insertion of complete dentures, this study was done to compare the flow rate of unstimulated and stimulated whole saliva before, during, and after the insertion of complete dentures in different age group. ${ }^{4,6,7,9}$

In the present study, the stimulated salivary flow rate was higher than the unstimulated flow at all times. The maximum increase in salivary flow rates for both unstimulated and stimulated saliva was found immediately after denture insertion that was $0.60 \pm 0.241 \mathrm{ml} / \mathrm{min}$ and $0.93 \pm 0.41 \mathrm{ml} / \mathrm{min}$ respectively. The unstimulated salivary rate was lowest before denture insertion with mean values of $0.27 \mathrm{ml} / \mathrm{minute}$ with values ranging from 0.08 to 0.70 . The highest flow rate was recorded during denture insertion with mean values of $0.60 \mathrm{ml} / \mathrm{min}$ and values ranging from 0.26 to 1.28 . The mean stimulated salivary rate was lowest before denture insertion with mean values of $0.59 \mathrm{ml} /$ minute with values ranging from 0.18 to 1.50 . The highest flow rate was recorded during denture insertion with mean values of $0.93 \mathrm{ml} /$ minute and values ranging from 0.24 to 2.40 .

This result is in unison with the results of studies done by Yurdukoru et, Wolff et al, Matsuda et al, Muddugangadhar et al, Tango et al, where there was an increase in salivary flow rates immediately after insertion of complete dentures., ${ }^{5,9}$ Immediately following insertion, the dentures are perceived as foreign bodies in the mouth thereby stimulating the salivary glands to increase salivary production. This explains the increased flow rate of saliva immediately after insertion of a complete denture.

In this study, the unstimulated and stimulated salivary flow after 7 days of denture insertion was $0.50 \pm 0.19 \mathrm{ml} / \mathrm{min}$ and $0.75 \pm 0.31 \mathrm{ml} / \mathrm{min}$ respectively. This value is less compared to at the day of insertion and 24 hours after insertion values but higher than that of pre-insertion levels. This may be explained by the fact that increased occlusal force because of dentures may make it possible for patients to chew better and eat greater amounts of food, stimulating the salivary glands more than before. It has been reported that an individual experiences a decrease in salivary flow rates after a short-term regimen on a soft or liquid diet. Conversely, an increase in the frequency of chewing or a change of diet to more rigid foods results in increased salivary flow rates. ${ }^{12}$ Yeh et al found salivary flow rates were significantly correlated with bite force for the whole saliva and stimulated parotid and stimulated sub-mandibular/ sub-lingual saliva. Matsuda et al. also found an increase in both unstimulated and stimulated whole salivary flow rates and maximal occlusal load after replacement of inadequate complete dentures with new dentures. ${ }^{7}$

In the present study, there was a trend of the gradual decrease in salivary flow rate with an increase in age but the association of age with salivary flow rates was not statistically significant implying no 
effect of age on salivary flow rates before, during (immediately after), 24 hours after and 7 days after denture insertion. The studies conducted by Heft and Baum, Jones et al, Ship et al, Muddugangadhar et al also concluded that salivary flow rates are not related to the age of individuals. ${ }^{13,14}$ The result of this study is in contrast with the study done by AlAzzawi et al found that salivary flow in males was significantly higher than in females and the change in flow rate of the whole saliva was related to age factor. $^{16}$

Based on this study, an increase in salivary flow rate of both unstimulated and stimulated saliva in different age groups following insertion of complete denture prosthesis was evident. There was a trend of a gradual decrease in salivary flow rate as age increases but there was no statistically significant correlation found. Thus, the general perception that aging has effects like dry mouth and hyposalivation does not hold true as for results of this study. However, the limitation of the study is the single-center study with simple random sampling and a wider population should be included in the study to come to solid conclusions.

\section{CONCLUSIONS}

Mean stimulated salivary flow rate was significantly higher than the unstimulated salivary rate before, during, and after denture insertion. There was an increase in both unstimulated and stimulated salivary flow rates during (immediately after), after 24 hours, and after 7 days of denture insertion as compared to before insertion of complete dentures. There is no statistically significant correlation between salivary flow rate and age before, during, after 24 hours, and after 7 days of insertion of complete dentures.

Recommendations: As observed in the study, salivary flow increases immediately after the insertion of complete dentures. This phenomenon may result in discomfort in the patient immediately after receiving new dentures. At the time of denture, insertion clinician should explain that new dentures are perceived as foreign objects, stimulating the salivary glands to produce excess saliva, which necessitates frequent deglutition.

\section{REFERENCES}

1. Sachdeva $S$, Noor R, Mallick R, Perwez E. Role of saliva in complete dentures: an overview. Annals of Dental Speciality.2014;2(2):51-54. [Google Scholar]

2. Humphrey SP, Williamson RT. A review of saliva: normal composition, flow, and function. J Prosthet Dent. 2001;85(2):162-9.https:// doi.org/10.1067/mpr.2001.113778.[Google Scholar] [PubMed]

3. Navazesh M. Methods for collecting saliva. Ann N Y Acad Sci. 1993;694:72-7. https://doi. org/10.1111/j.[Google Scholar]

4. Yurdukoru B, Terzioblu H, Yilmaz T. Assessment of whole saliva flow rate in denture wearing patients. Journal of Oral Rehabilitation. 2001;28(1):109-12. https://doi.org/10.1046/ j.1365-2842.2001.00624.x.[Google Scholar] [PubMed]

5. Tango RN, Arata A, Borges ALS, Costa AKF, Pereira LJ, Kaminagakura E. The Role of New Removable Complete Dentures in Stimulated Salivary Flow and Taste Perception. J Prosthodont. 2018;27(4):335-9. https://doi. org/10.1111/jopr.12507.[Google Scholar] [PubMed]

6. Muddugangadhar B, Sangur R, Rudraprasad I, Nandeeshwar D, Dhanya Kumar B. A clinical study to compare between resting and stimulated whole salivary flow rate and $\mathrm{pH}$ before and after complete denture placement in different age groups. The Journal of Indian Prosthodontic Society. 2015;15(4):356- 66. https://doi.org/10.4103/0972-4052.164907. [GoogleScholar] [PubMed]

7. Matsuda K, Ikebe K, Ogawa T, Kagawa R, Maeda $Y$. Increase of salivary flow rate along with improved occlusal force after the replacement of complete dentures. Oral Surg Oral Med Oral Pathol Oral Radiol Endod. 2009;108(2):211-5. https://doi.org/10.1016/j.tripleo.2009.03.020. [Google Scholar] [PubMed]

8. Nagler RM. Salivary glands and the aging process: mechanistic aspects, health-status and medicinal-efficacy monitoring. Biogerontology. 2004;5(4):223-33. https://doi.org/10.1023/ B:BGEN.0000038023.36727.50 [Google Scholar] [PubMed]

9. Wolff A, Ofer S, Raviv M, Helft M, Cardash HS. The flow rate of whole and submandibular/ sublingual gland saliva in patients receiving replacement complete dentures. J Oral Rehabil. 2004;31(4):340-3. https://doi.org/10.1046/ j.1365-2842.2003.01247.x.[Google Scholar] [PubMed]

10. Nonzee V, Manopatanakul S, Khovidhunkit SO. Xerostomia, hyposalivation and oral microbiota 
in patients using antihypertensive medications. J Med Assoc Thai. 2012;95(1):96-104. [Google Scholar]

11. Shekhar A, Das S, Bhattacharyya J, Goel P, Majumdar S, Ghosh S. A comparative analysis of salivary factors and maxillary denture retention in different arch forms: An in vivo study. The Journal of Indian Prosthodontic Society. 2018;18(1):53-60. https://doi.org/10.4103/jips. jips_110_17 [Google Scholar][PubMed]

12. Yeh $C K$, Johnson DA, Dodds MW, Sakai $S$, Rugh JD, Hatch JP. Association of salivary flow rates with maximal bite force. J Dent Res. 2000;79(8):1560-5. https://doi.org/10.1177/00 220345000790080601 [Google Scholar]

13. Heft MW, Baum BJ. Unstimulated and stimulated parotid salivary flow rate in individuals of different ages. J Dent Res. 1984;63(10):1182-5. https://doi.
org/10.1177/00220345840630100101[Google Scholar][PubMed]

14. Jones RE, Ship JA. Major salivary gland flow rates in young and old, generally healthy African Americans and whites. Journal of the National Medical Association. 1995;87(2):1315. [GoogleScholar]

15. Ship JA, Nolan NE, Puckett SA. Longitudinal analysis of parotid and submandibular salivary flow rates in healthy, differentaged adults. J Gerontol A Biol Sci Med Sci. 1995;50(5):M285-9.https://doi.org/10.1093/ gerona/50a.5.m285[Google Scholar][PubMed]

16. Al-Azzawi SI, Alwan AM, Salal RH. Influence of age and gender on salivary flow rate in completely edentulous patients. Mustansiriya Dental Journal. 2018;10(1):64-8 access: [Google Scholar]

\section{$* * *$}

